\title{
Ready to Move: A Unique University Worksite Wellness Initiative
}

\author{
Mariah Deinhart, MPH, CHES \\ Carol Kennedy-Armbruster, PhD, FACSM, C-EP \\ School of Public Health/Department of Kinesiology \\ Indiana University - Bloomington
}

\begin{abstract}
Background: Ready to Move (RTM), a university worksite wellness program, was implemented to get employees moving more and sitting less by combining student health coaching and activity trackers (AT's). Aim: This article provides program specifics and survey data outcomes to facilitate ideas for university faculty, staff and student collaboration. The intent of the article is to provide an example of how academic classes can contribute to employee worksite wellness programming within a university.

Methods: Twelve cohorts (2015 - 2017) comprised of 295 university employees received Fitbit Flex ATs and health coaching from students enrolled in a physical activity (PA) behavioral interventions class during a 10-week program. The employees met with their student coach eight times to learn how to use their AT and set movement goals. Employee's completed self-reported surveys on average PA days and PA confidence pre/post program.

Results: Findings revealed RTM significantly impacted employees average number of PA days and their confidence in ability to sustain PA. Employee qualitative comments revealed RTM instilled the importance of utilizing ATs combined with student engagement made the experience enjoyable and effective.
\end{abstract}

Conclusion: RTM's combination improved employee movement outcomes and provided additional programming ideas for the employee wellness program at a large Midwestern university.

Submitted 8 October 2018: accepted 2 March 2019

Keywords: university worksite, activity trackers, physical activity, confidence

The 2018 Office of Disease Prevention and Health Promotion's (ODPHP) physical activity scientific report concluded that physical activity bouts of any length of time contribute to the health benefits associated with the accumulated volume of physical activity. This 2018 scientific recommendation is different from the 2008 ODPHP recommendation that stated that physical activity occur in 10-minute continuous bouts. The 2018 ODPHP scientific report points to the need to shift the focus to encouraging physical activity throughout the day. This change may be critical in reducing the anxiety many non-movers experience when considering their initial steps to moving more. In order for these initial steps to take place, a distinction between exercise and physical activity is essential. Exercise is often associated with activities performed in a gym setting whereas physical activity is any bodily movement produced by skeletal muscles requiring energy expenditure (World Health Organization, 2018). This bodily movement can include household chores, playing, working, and countless recreational activities. By turning the focus to physical 
activity, non-movers may find movement activities they not only enjoy but also can maintain. Getting the non-moving population to enjoy movement may prove to have the greatest impact on our nation's health over time. Walking is an activity many people find enjoyable and can obtain health benefits from (Sullivan \& Lachman, 2017). The American Heart Association (AHA, 2014) states that walking 30 minutes a day can improve blood pressure, reduce the risk for coronary heart disease and stroke, boost mental wellbeing, support a healthy weight, as well as reduce the risk of osteoporosis, type II diabetes, and breast and colon cancer. Consequently, simply walking more throughout the day can "count" towards improving health and well-being. Technology applications, including wearable devices and smartphones, have helped reinforce the concept that cumulative steps per day is important and relevant to health outcomes. These devices reinforce the concept that any movement "counts" towards improving health and wellbeing. The ACSM Worldwide Survey of Fitness Trends (Thompson, 2018) named wearable technology in the top five trends for the past three years. Forbes (Marr, 2016) suggests this trend will continue to grow. Activity trackers monitor daily activity and track the user's movement while incorporating goal setting, feedback, social support, and rewards into the device's compatible smartphone applications.

Segar (2017), a behavioral sustainability scientist, points out how wearable technology and their smartphone applications have allowed the anti-gym and non-mover population to find their own, comfortable form of movement. Individuals who dislike traditional exercise or are uncomfortable in a gym setting are prime users for wearable technology due to its ability to provide personalized, immediate, digital proof of how much movement they are accumulating. Meeting the daily moderate to vigorous physical activity (MVPA) guidelines requires 7,000-8,000 steps/day for adults (Tudor-Locke et al., 2011). Segar suggests that continual feedback is essential in successfully pursuing and achieving goals. Wearable devices show the accumulated step count directly on the device's screen. This accumulated step count in addition to the device's movement reminders help combat sedentarism, identified as a major risk factor for all-cause mortality and particularly heart disease (Benatti \& Ried-Larsen, 2015). Users can view how many steps they received compared to the previous day, week, month, or year. Segar argues that although these devices are valuable tools for reaching goals, they are only tools. In order to sustain motivation, it must come from within oneself.

Despite wearable technology's strengths of including goal setting, feedback, rewards, and social support, Sullivan \& Lachman (2017) mention some critical behavior change strategies missing from these devices. Action planning is a strategy that includes "if, then" plans. This motivates individuals to plan how, when, and where to achieve goals. Through action planning, individuals can identify previous barriers preventing goal achievement. By addressing barriers, it is possible to overcome obstacles. Wearable devices do not contain action planning and barrier identification strategies crucial for physical activity long-term goal attainment. Inactive individuals need specific strategies in order to sustain daily movement practices. Wearable devices incorporate behavior change information, yet more behavioral strategies and human coaching may help sustain change.

Health and fitness professionals' effort to change sedentary lifestyles and sustain movement have been largely unsuccessful. With an approximate 80\% exercise program dropout rate, it's been suggested that health and fitness professionals struggle to properly motivate clients (Gidlow, Johnston, Crone, \& James, 2005; Abbott, 2014). Wolever et al. (2013) defined health coaching as a client-centered process that includes client-determined goals, integrates learning and self-discovery, provides education, and encourages health behavior accountability. Enhancing communication skills like providing feedback, emotional support, and expressing empathy coupled with training in behavior change techniques and health behavior models are most relevant in preparing health coaches (Wolever et 
al., 2013). Sforzo, Moore, and Scholtz (2015) proposes that health coaching creates sustainable behavior change by helping clients become more responsible, mindful, resilient, self-compassionate, and more fully engaged in leading a healthy lifestyle. This develops a client's motivation and confidence.

According to Sforzo et al. (2015) health coaches take off their "expert" hat, foster possibilities, ask effective questions and help clients elicit their agenda. If these questions and possibilities are client-centered, the coach can be a facilitator of change, and a partner in the process (Sforzo et al., 2015). Rutjes, Willemsen, Kersten-van Dijk, De Ruyter, and Ijsselsteijn (2017) compiled data from semi-structured interviews with health coaches who had an average of 10 years of experience. Each health coach expressed the importance of a tailored approach with clients. The more specific and tailored advice, the more likely the client is to adhere. Based on the daily lives of each client, health coaches work to elicit change over time. Coaches encourage a systematic change process with the client "driving the bus." Each client will have their own path with distinct successes and setbacks.

\section{METHODS}

Survey data were collected from 295 university employees enrolled in a 10-week PA program called Ready to Move (RTM) offered through the University employee wellness program in collaboration with the School of Public Health (SPH) Department of Kinesiology's academic class. This total number of employees consisted of 12 cohorts spanning from Fall of 2015 to Spring of 2017. Total students involved in delivering the program was 218. The university employees received a FitBit Flex activity tracker as well as individual health coaching from the students enrolled in the Department of Kinesiology's physical activity (PA) behavioral interventions class. The Fitbit Flex ${ }^{\circledR}$ was chosen by the university wellness program directors because of cost and ease of use (Kiessling \& Kennedy-Armbruster, 2016). The university wellness program recruited the employees for this project through marketing and an organized sign up process. The employees, paired with a student coach, were required to meet together eight times throughout the semester outside of classroom. A coaching/tracking combination was encouraged through academic content taught in the classroom. During these meetings, the employees learned how to use their AT's and set movement goals. Because the student coach was enrolled in an academic class, meeting with and coaching their assigned employee was attributed to a grade. Employees were made aware that a student's grade was dependent upon their participation in this program. This outside of class experience allowed students to practice their coaching skills on real people striving to change and helped hold employees accountable in meeting with their student coach. Pre/post program selfreported surveys on average PA days and PA confidence were administered to employee's.

Student health coaches were educated on behavior change techniques, motivational interviewing strategies and the coach versus expert approach. In addition to educating their clients on how to use ATs, the students applied the classroom material by coaching their clients through behavior change utilizing specific, measurable, attainable, realistic, time-bound (SMART) goal setting and motivational interviewing techniques practiced in class. The students focused on what the client was interested in whether it was exercise (ACSM guidelines), Physical Activity (ODPHP, 2018) or reducing sedentary time during the workday. This Human Movement Paradigm (Figure 1; Armbruster, Evans, \& Laughlin, 2019; Kennedy-Armbruster, Evans, \& Reed, 2019) was presented throughout the class as an idea for what to discuss with clients in terms of physical activity options paying particular attention to physical activity during the workday. 
Michelle Segar discusses the importance of clients wanting to participate in movement and transforming "I should" statements to "I want" (Segar, 2015). She explains the detrimental effects of movement feeling like a chore. When the RTM clients were asked, "What movement activities do you enjoy?" the most common answer was walking (Figure 2). This was an important realization as the student health coaches encouraged activities employees wanted to do. There was limited gym-talk as the focus was on work and home-based movement. Workstation movements to perform at a desk, strategies to move throughout the workday, and building at-home movement routines were encouraged throughout the program.

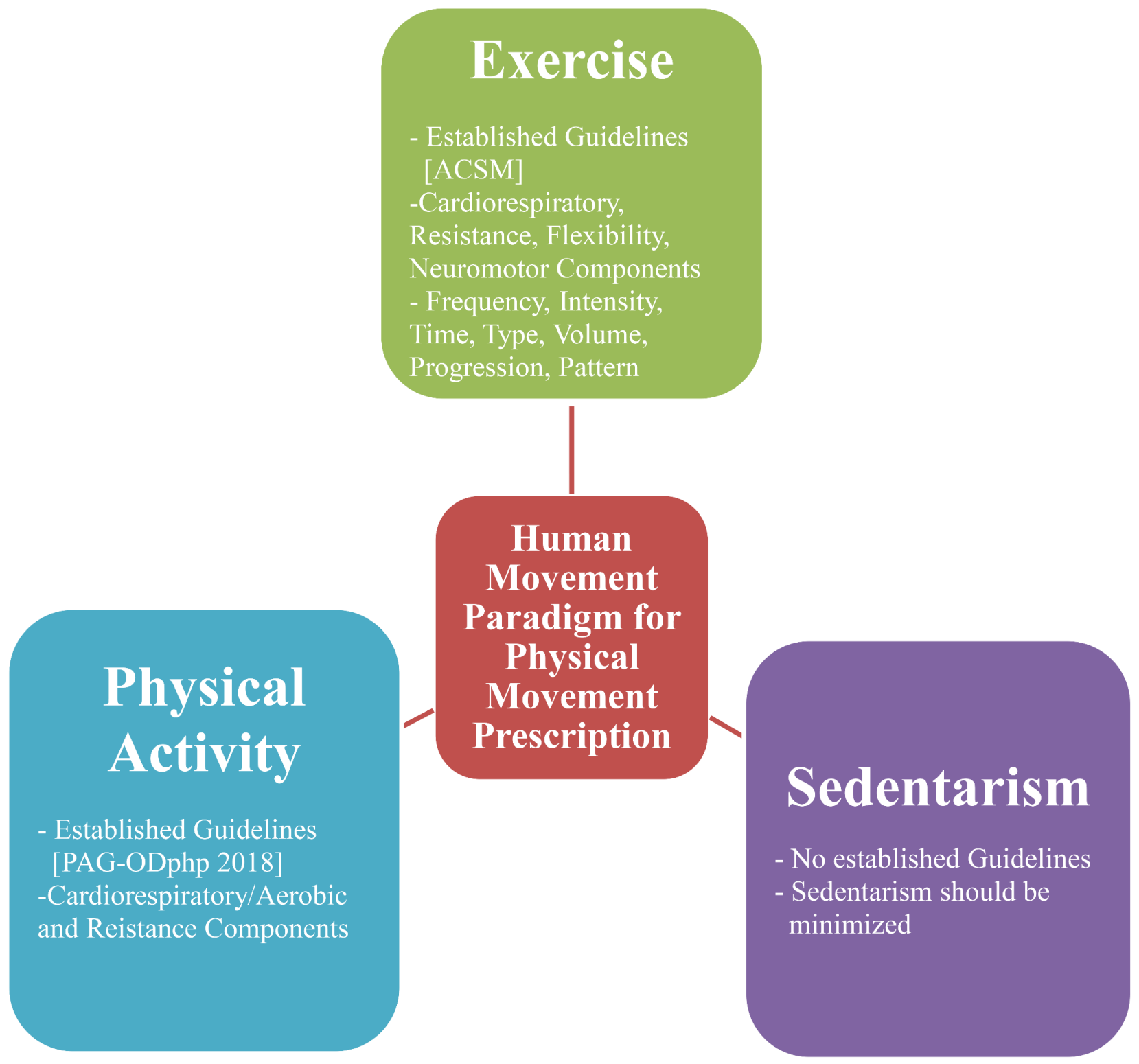

Figure 1. Human Movement Paradigm 


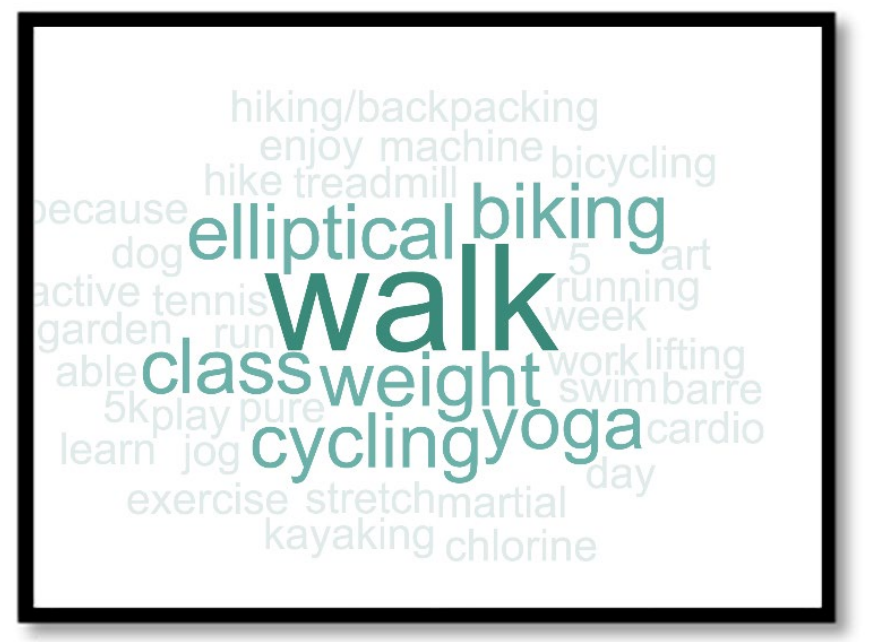

Figure 2. Word cloud created from the survey question "What movement activities do you enjoy?"

\section{RESULTS}

Pre and post RTM program surveys were completed by employees to measure behavioral outcomes and evaluate the program's impact. Results from 12 cohorts comprising 295 employees found both a statistically significant $(p<.001)$ increase in the number of days clients participated in physical activity (Figure 3) as well as their confidence in ability to sustain physical activity (Figure 4).

Question Utilized: In the average workweek, how many days do you get 30 minutes or more (for at least 10 minutes at a time) of light to moderate physical activity? Examples include walking, pushing a lawn mower, or slow cycling.

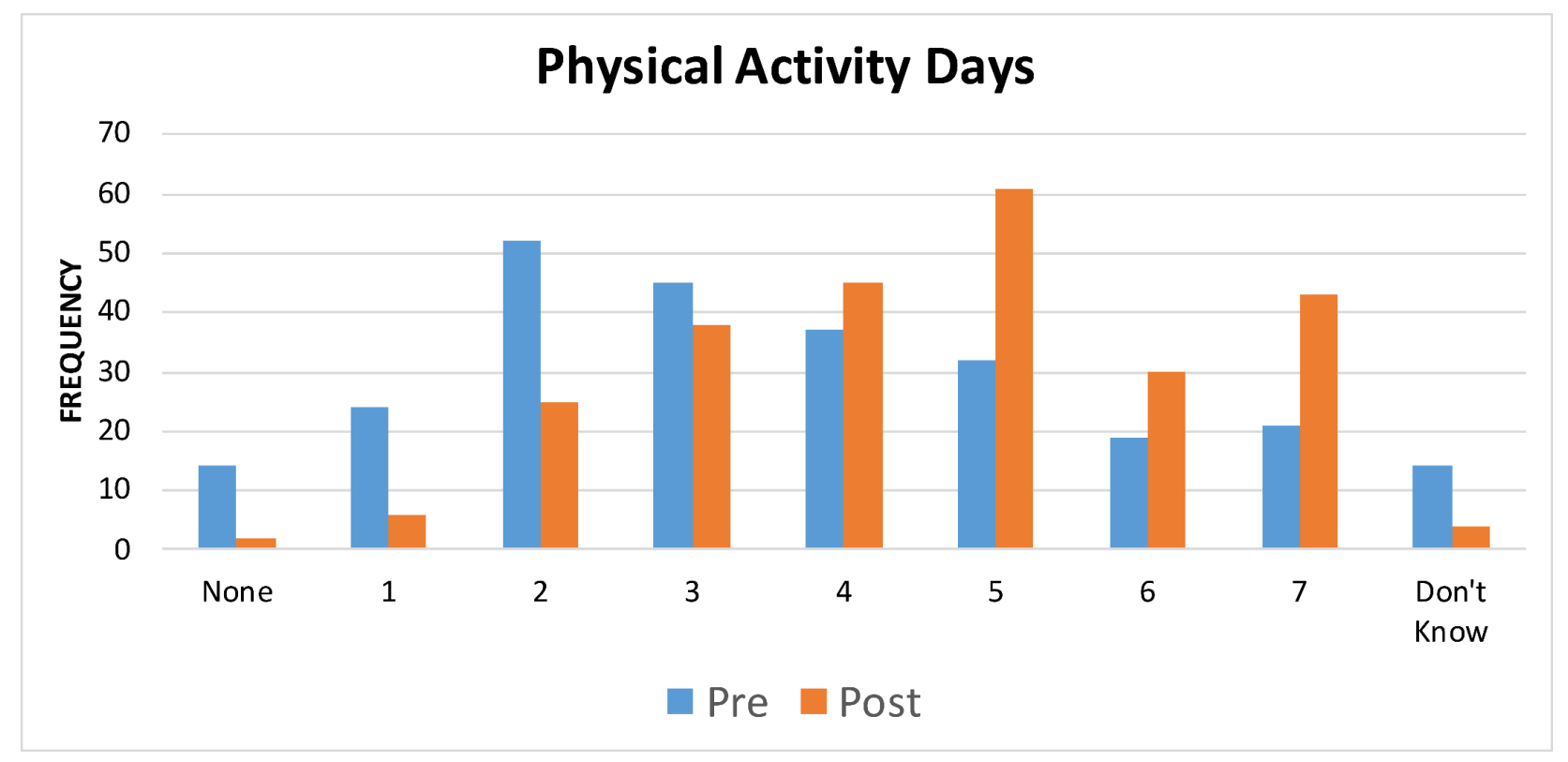

Figure 3. Pre/post comparison representing a significant increase in PA days

The number of days clients participated in physical activity significantly increased with a mean difference of 1.087. 
Question Utilized: My confidence level in my ability to reach and sustain regular physical activity/movement:

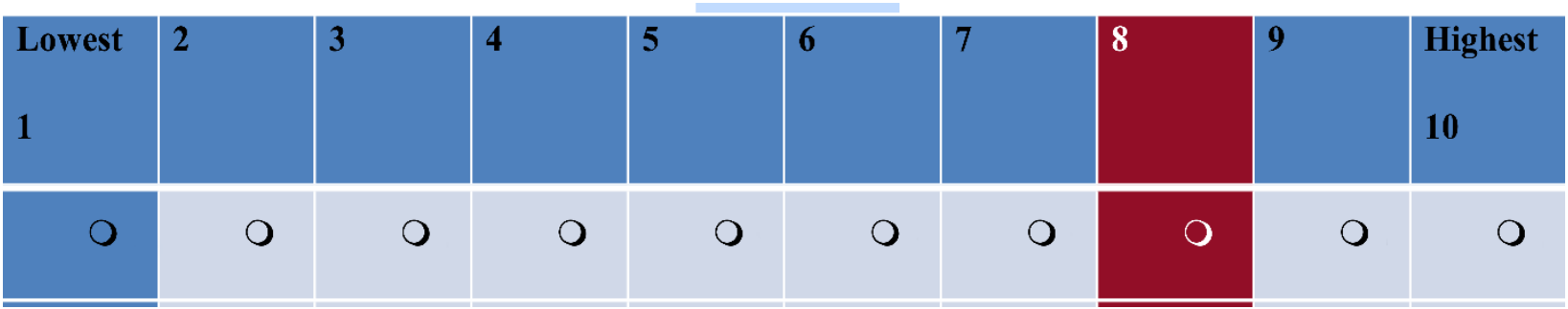

Figure 4. RTM pre/post survey confidence scale.

Post program average in confidence was 8.06. There was a significant increase pre to post program with a mean difference of 0.927 .

Overall, significant increases in client's average days of PA and confidence in ability to sustain PA were found with this 10 -week RTM program combining activity trackers and student health coaching.

\section{QUALITATIVE RESULTS}

Table 1

\section{Client Comments on ATs}

"The tracker makes me accountable and makes me want to do more"

"The tracker made me aware of how little I was moving during the day. I was often surprised the first couple of weeks to find out how much, or really how little, I walked between the time I arrived at work and the time I left. After recognizing this lack of movement, the fitness tracker gave me specific, easily measurable goals to work toward. It was easy to see at a glance how much activity I'd gotten so far that day, and I frequently made adjustments partway through the day to get more steps. I've gotten better at estimating steps now, so that even on days I forget to wear my Fitbit, I can still keep track of generally where I'm at with my steps."

"The tracker provided more accountability and a specific goal to reach. The goal of working out every day is vague and wasn't motivating all the time. The tracker provided specific goals and also feedback when those goals were met." 
Table 2

Explanations From Clients who Answered yes to, "Has This Program Changed Your Views on Physical Activity?"

'I no longer see movement as 'all or nothing.' Every little bit can make an impact"

"My coach helped me to think about exercise not only as something that happens at the gym, but instead should incorporate movement throughout my day, including many activities I enjoy and could do more while having fun and feeling good."

"I generally tend to think of 'exercise' as something difficult and time-consuming; this program has helped me to see how to fit short bursts of activity into my normal life."

"I have always exercised, but it has been more point in time. This program is about moving more throughout day. Maybe a good parallel is small meals over the course of the day instead of one big meal."

\section{DISCUSSION}

The results point to the idea that ATs combined with student health coaching accountability can play a role in increasing movement awareness and providing movement motivation in a university environment. Which factor plays a greater role in the outcomes could not be determined. Sforzo et al. (2015) suggests when the responsibility of goal setting shifts to the client, the client becomes empowered to make sustainable behavior change. The technique used in this program is different from an "exercise prescription" that has followed more of a medical model of intervening in lifestyle change. Bloomfield (2017) believes there is a need to translate science into practice. The authors did their best to repeat the intervention for several years before reporting outcome data to help strengthen data outcome reliability. Others like Rutjes et al. (2017) suggested through their work that there are clear benefits to the combination of wearables and health coaching which was also found in the RTM program outcomes. The number one takeaway from the RTM program was to MAKE time to MOVE throughout the day (Fig. 5). 


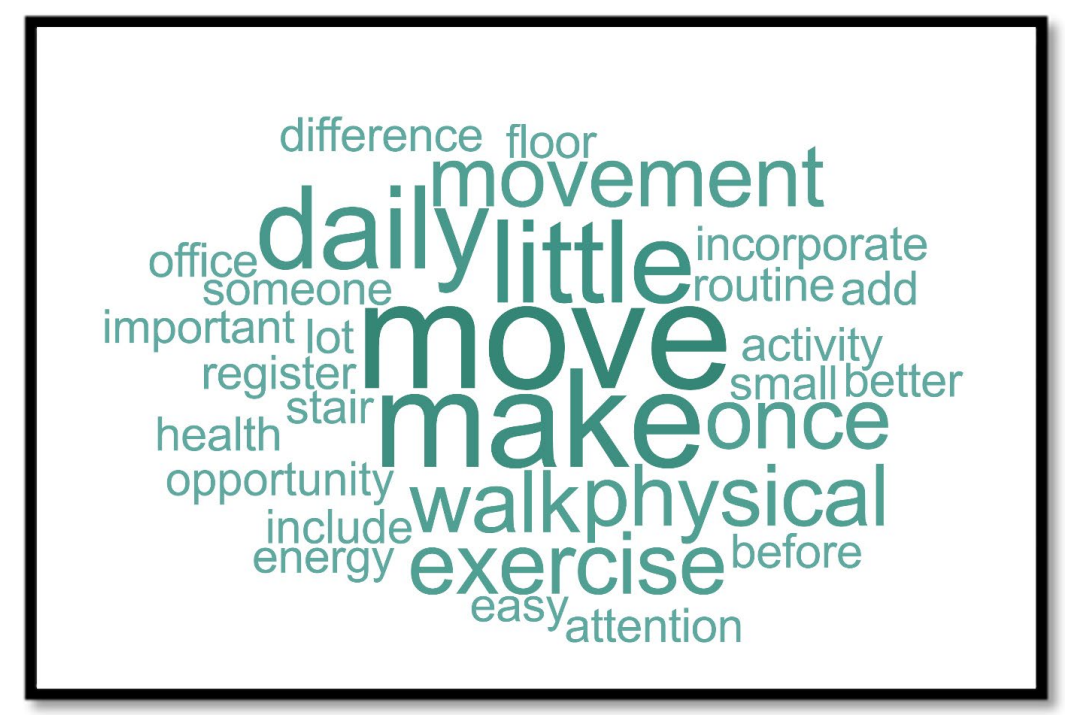

Figure 5. Word cloud created from the survey question "What is the number one take-a-way from your participation in the Ready to Move program?”

\section{CONCLUSION}

Taking the coach approach, finding movement activities that participants enjoy, making goal setting the participant's responsibility, in combination with utilizing wearable devices for immediate and objective feedback may help increase physical activity and decrease time spent in sedentary behavior. The 2018 Physical Activity Guidelines Scientific Report is relatively new, but this RTM program outcomes reflected their recommendation of the need to replace sedentary behavior with light-intensity physical activity as well as reduce time spent in sedentary behavior. Program ideas that foster and encourage these strategies may help increase the physical activity of sedentary participants in an academic worksite community. The program's success has worked to create additional movement programs incorporating faculty, students, and employees utilizing the wellness program. Faculty looking for enhanced teaching methods, students wanting hands-on learning, and employees working towards better health in a university setting was enough to make an impact for all at this large Midwestern university. More specific analysis related to which aspect of the program had the highest impact (i.e., tracker, coaching, student accountability) is needed in order to have a better understanding. However, overall it was an effective program for enhancing days of physical activity, confidence and community engaged experiences between students and university employees. 


\section{REFERENCES}

Abbott, A. A. (2014). Philosophy \& Standards Part II. ACSM's Health \& Fitness Journal, 18(1), 34-38. https://doi.org/10.1249/FIT.0000000000000010

American Heart Association. (2014). American Heart Association recommendations for physical activity in adults. Retrieved from http:/ /www.heart.org/HEARTORG/HealthyLiving/PhysicalActivity/FitnessBasics/American-HeartAssociation-Recommendations-for-Physical-Activity-in-Adults_UCM_307976_Article.jsp\#.WsEFcdPwY0o

Armbruster, C.K., Evans, E., \& Laughlin, C. (2019). Fitness and Wellness: A Way of Life, Human Kinetics Publisher, Champaign, IL.

Benatti, F. B., \& Ried-Larsen, M. (2015). The effects of breaking up prolonged sitting time: a review of experimental studies. Medicine \& Science in Sports \& Exercise, 47(10), 2053-2061. https://doi.org/10.1249/MSS.0000000000000654

Bloomfield, S. (2017). Translating Clinical Science to Clinical/Real World Applications: Relevance to Exercise Science. ACSM Translational Journal, 2(22), 146-147.

Gidlow, C., Johnston, L. H., Crone, D., \& James, D. (2005). Attendance of exercise referral schemes in the UK: A systematic review. Health Education Journal, 64(2), 168-186. https://doi.org/10.1177/001789690506400208

Kennedy-Armbruster, C.A., Evans, E., \& Reed, R. (2019). Exercise prescription for the apparently healthy. ACSM Clinical Exercise Physiology, $1^{\text {st }}$ Edition, Ch. 4., Wolters Kluwer Publishers.

Kiessling, B., \& Kennedy-Armbruster, C. (2016). Move More, Sit Less, And Be Well. ACSM's Health \& Fitness Journal, 20(6), 26-31.

Marr, B. (2016). 15 noteworthy facts about wearables in 2016. Retrieved from https://www.forbes.com/sites/bernardmarr/2016/03/18/15-mind-boggling-facts-about-wearables-in2016/\#450785182732

Office of Disease Prevention and Health Promotion (2008). Physical activity guidelines for Americans. Retrieved from https://health.gov/paguidelines/guidelines/.

Office of Disease Prevention and Health Promotion. (2018). The 2018 Physical Activity Guidelines Advisory Committee Scientific Report. Retrieved from https://health.gov/paguidelines/second-edition/report.aspx

Rutjes, H., Willemsen, M. C., Kersten-van Dijk, E. T., de Ruyter, B. E. R., \& IJsselsteijn, W. A. (2017). Better together: opportunities for technology in health coaching from the coach's perspective. E-Coaching for Health and Wellbeing (eCHW-2017), pp. 1-14.

Segar, M. L. (2017). Activity Tracking and Motivation Science: Allies to Keep People Moving for a Lifetime. ACSM's Health \& Fitness Journal, 21(4), 8-17.

Segar, M. (2015). No sweat: how the simple science of motivation can bring you a lifetime of fitness. AMACOM Div American Mgmt Assn. 
Sforzo, G. A., Moore, M., \& Scholtz, M. (2015). Delivering change that lasts: health and wellness coaching competencies for exercise professionals. ACSM's Health \& Fitness Journal, 19(2), 20-26.

Sullivan, A. N., \& Lachman, M. E. (2017). Behavior change with fitness technology in sedentary adults: a review of the evidence for increasing physical activity. Frontiers in public bealth, 4, 289. https://doi.org/10.3389/fpubh.2016.00289

Thompson, W. R. (2018). Worldwide survey of fitness trends for 2018. ACSMs Health Fit J, 21(6), 10-19. https://doi.org/10.1249/FIT.0000000000000341

Tudor-Locke, C., Craig, C., Brown, W., Clemes, S., De Cocker, K., Giles-Corti, B., Hatano, Y., Inoue, S., Matsudo, S., Mutrie, N., Oppert, JM., Rowe, D., Schmidt, M., Schofield, G., Spence, J., Teixeira, P., Tully, M., \& Blair, S. (2011). How many steps/day are enough for adults? International Journal of Behavioral Nutrition and Physical Activity, 8(79), 1. https://doi.org/10.1186/1479-5868-8-79

Wolever, R. Q., Simmons, L. A., Sforzo, G. A., Dill, D., Kaye, M., Bechard, E. M., \& Yang, N. (2013). A systematic review of the literature on health and wellness coaching: defining a key behavioral intervention in healthcare. Global Advances in Health and Medicine, 2(4), 38-57. https://doi.org/10.7453/gahmj.2013.042

World Health Organization. (2018). Physical activity. Retrieved from http://www.who.int/mediacentre/factsheets/fs385/en/.

Please address correspondence to:

Mariah Deinhart

Department of Kinesiology

Indiana University - Bloomington

Bloomington, IN 47405

Tel: 641-420-2087

mariahdeinhart@gmail.com

\section{Author Note}

The authors would like to thank Patty Hollingsworth, Director of Healthy IU, Samantha Schaefer, Healthy IU Manager, IUB, IUE, IUS and Julie Newsom, Healthy IU Communication Specialist for their support, assistance, and belief in the importance of combining academic and service opportunities for the benefit of both students, faculty and staff. Without their support and assistance, the RTM program would not have flourished like it did at Indiana University. 